\title{
Economics of Long-Term Business Relationships
}

\section{Masao Nakamura*}

University of British Columbia, Canada

The automobile industry is typically characterized by large assembly plants and many suppliers who deliver over 20,000 auto-parts to the assembly plants. How to organize the inter-firm relationships between assembler and supplier firms involving so many parts has always been an important managerial issue.

In his article in Business Week ("A Japanese buddy system that could benefit U.S. business," October 1991) Alan Blinder points out that while most American companies consider as the two alternative organizational forms for inter-firm relationships vertical integration and arm's-length purchases in the marketplace and that different companies blend them in different proportions. We know well by now that the potential incentive issues for these organizational forms. Vertically integrated parts production being a part of a large assembly manufacturer like General Motors enjoys the advantage of a centrally controlled production system integrating the parts production into the assembly lines. But it could easily suffer from inefficiencies (the agency cost) arising from the firm's large size. On the other hand, purchasing parts in the open market means the assembler may suffer from suppliers' opportunistic behavior and the difficulty in synchronizing their parts delivery with the needs of the assembly lines.

Blinder in this article discusses Japan's production keiretsu (also called capital keiretsu) which consists of suppliers and the core assembler company all in long-term business relationships. For example, Toyota Motor Company's production keiretsu group consists of Toyota itself in the center surrounded by Toyota's first-tier suppliers (e.g. Denso, Aisin Seiki) which in turn have their own keiretsu involving second-tier suppliers, and on. Other Japanese auto assembler manufacturers as well as other assembly based manufacturers such as electronics products manufacturers generally have their own production keiretsu groups; though the level of cohesion within each group varies with the Toyota group being the most cohesive. Keiretsu suppliers are typically partially owned by their core assembly companies but the average ownership level is non-controlling $10-25 \%$. Still in the long run, these shares are good enough to exert some influence on suppliers. This level of share ownership compares with vertically integrated parts production $(100 \%$ ownership) and arms-length purchasing (typically 0\%). Japanese production keiretsu suppliers produce primarily for their core assemblers. But interestingly, they also produce for other assemblers who are their primary core assembler's competitors to gain economies of scale. The core assembler companies find it easier to involve their keiretsu suppliers in their new product development projects than arms-length suppliers, because keiretsu members are more trustworthy, in their view, than other suppliers and they try harder also. Being a separate company, a keiretsu supplier's unit cost is significantly lower than that of vertically integrated operations. Blinder describes keiretsu relationships as "the sturdy, but not indestructible, relationships," that seem to combine artfully the contrasting virtues of hierarchical control and market competition. Another advantage of production keiretsu suppliers is that, because of their long-term relationships with the assembler companies, implementing assembly companies' just-in-time production systems, a corner stone of contemporary assembly based manufacturing system developed by Toyota, is easier with keiretsu suppliers than with arms-length suppliers.
Despite various advantages of production keiretsu, their negative aspects surfaced during the 1990s after the burst of Japan's financial bubble in 1990. What happened then? In electronics manufacturing industry in particular, where assembly operations are very extensive as in the auto industry, many parts including core parts began to be made of memory, processor and other semi-conductor chips, and other digital-age components, which were more easily made than before using proper machinery with relatively little trained workers. Keiretsu suppliers in the electronics industry in Japan lost their competitive advantages, since their high skill level became less relevant and their unit cost became too high relative to their competitors' in developing countries in Asia. U.S. companies were able to switch to globally lowest cost suppliers promptly, while Japanese companies, because of their long-term relationships, had to continue saucing from their longterm suppliers at much higher cost. Japanese electronics companies lost the types of advantages they had developed over the previous decades in their production processes involving suppliers. Many Japanese assembler companies' presidents complained that their loss of competitive advantage comes mostly from the fact that they had to maintain their keiretsu suppliers, while their U.S. competitors were able to switch to the lowest-cost suppliers in China and elsewhere. This was made possible because of the technological shift in product lines in consumer markets from analog to digital products, which does not require the types of skill formation at the supplier level. This trend is also happening in the auto-industry though gradually, in part because car production still requires more integrated skill other than just digital components based assembly skill.

So the three alternative organizational forms of saucing supplies by assembler based manufacturing companies face time-varying circumstances, which provide varying degrees of advantages and disadvantages to these forms.

How assembler companies sauce their supplies requires careful calculation and comparison of the relative advantages and costs of these three organizational forms from both short-term and long-term horizons. The nature of new products that are emerging, the degree of sophisticated analog skill required in manufacturing products, macroeconomic conditions, changing wage levels in developing and developed countries, and many other factors determine what type of organizational form is appropriate for assembly based manufacturing operations.

*Corresponding author: Masao Nakamura, Professor, University of British Columbia, Canada, Tel: 604-822-8434; Fax: 604-822-8477; E-mail: masao.nakamura@gmail.com

Received December 13, 2012; Accepted December 14, 2012; Published December 15, 2012

Citation: Nakamura M (2013) Economics of Long-Term Business Relationships. J Bus \& Fin Aff 2:e123. doi:10.4172/2167-0234.1000e123

Copyright: (c) 2013 Nakamura M. This is an open-access article distributed under the terms of the Creative Commons Attribution License, which permits unrestricted use, distribution, and reproduction in any medium, provided the original author and source are credited. 